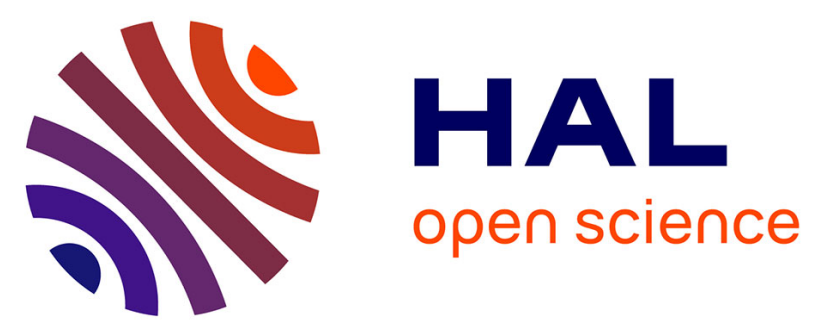

\title{
Detection of circulating tumor cells in breast cancer may improve through enrichment with anti-CD146
}

Bianca Mostert, Jaco Kraan, Joan Bolt-de Vries, Petra Spoel, Anieta M.

Sieuwerts, Mieke Schutte, Annemieke M. Timmermans, Renée Foekens, John

W. M. Martens, Jan-Willem Gratama, et al.

\section{To cite this version:}

Bianca Mostert, Jaco Kraan, Joan Bolt-de Vries, Petra Spoel, Anieta M. Sieuwerts, et al.. Detection of circulating tumor cells in breast cancer may improve through enrichment with anti-CD146. Breast Cancer Research and Treatment, 2010, 127 (1), pp.33-41. 10.1007/s10549-010-0879-y • hal-00594475

\section{HAL Id: hal-00594475 \\ https://hal.science/hal-00594475}

Submitted on 20 May 2011

HAL is a multi-disciplinary open access archive for the deposit and dissemination of scientific research documents, whether they are published or not. The documents may come from teaching and research institutions in France or abroad, or from public or private research centers.
L'archive ouverte pluridisciplinaire HAL, est destinée au dépôt et à la diffusion de documents scientifiques de niveau recherche, publiés ou non, émanant des établissements d'enseignement et de recherche français ou étrangers, des laboratoires publics ou privés. 
Detection of circulating tumor cells in breast cancer may improve through enrichment with anti-CD146

Bianca Mostert ${ }^{1,2}$, Jaco Kraan ${ }^{1}$, Joan Bolt-de Vries $^{2}$, Petra van der Spoel ${ }^{1}$, Anieta M.

Sieuwerts ${ }^{2}$, Mieke Schutte ${ }^{3}$, Annemieke M. Timmermans ${ }^{2}$, Renée Foekens ${ }^{2}$, John W.M.

Martens $^{2}$, Jan-Willem Gratama ${ }^{1}$, John A. Foekens ${ }^{2}$, Stefan Sleijfer ${ }^{1,2}$

${ }^{1}$ Department of Medical Oncology, Daniel den Hoed Cancer Center and Laboratory of

Translational Tumor Immunology, Erasmus MC, Rotterdam, the Netherlands

${ }^{2}$ Department of Medical Oncology, Josephine Nefkens Institute and Cancer Genomics Center, Erasmus MC, Rotterdam, the Netherlands

${ }^{3}$ Department of Medical Oncology, Josephine Nefkens Institute and Laboratory of Tumor Biology and Pharmacogenomics, Erasmus MC, Rotterdam, the Netherlands

\section{Funding:}

This work was in part financially supported by the Netherlands Genomic Initiative (NGI)/Netherlands Organization for Scientific Research (NWO).

\section{Correspondence to:}

Bianca Mostert

Erasmus MC, Daniel den Hoed Cancer Center, Room D2-61

Groene Hilledijk 301

3075 EA Rotterdam

The Netherlands

Telephone: +31107041324

Fax: +31 107041005

Email: b.mostert@erasmusmc.nl

Key words:

Circulating tumor cells; breast cancer; CellSearch; CD146; minimal residual disease; EpCAM 


\section{Abstract}

\section{Purpose}

Most assays to detect circulating tumor cells (CTCs) rely on EpCAM expression on tumor cells. Recently, our group reported that in contrast to other molecular breast cancer subtypes, "normallike" cell lines lack EpCAM expression and are thus missed when CTCs are captured with EpCAM-based technology [1]. Here, the use of CD146 is introduced to detect EpCAM-negative CTCs, thereby improving CTC detection.

\section{Methods}

CD146 and EpCAM expression were assessed in our panel of 41 breast cancer cell lines. Cells from 14 cell lines, 9 of which normal-like, were spiked into healthy donor blood. Using CellSearch ${ }^{\mathrm{TM}}$ technology, $7.5 \mathrm{~mL}$ whole blood was enriched for CTCs by adding ferrofluids loaded with antibodies against EpCAM and/or CD146 followed by staining for Cytokeratin and DAPI. Hematopoietic cells and circulating endothelial cells (CECs) were counterstained with CD45 and CD34, respectively. A similar approach was applied for blood samples of 20 advanced breast cancer patients.

\section{Results}

Eight of 9 normal-like breast cancer cell lines lacked EpCAM expression but did express CD146. Five of these 8 could be adequately recovered by anti-CD146 ferrofluids. Of 20 advanced breast cancer patients whose CTCs were enumerated with anti-EpCAM and anti-CD146 ferrofluids, 9 had CD146+ CTCs.

\section{Conclusions}

Cells from breast cancer cell lines that lack EpCAM expression frequently express CD146 and can be recovered by anti-CD146 ferrofluids. CD146+ CTCs are present in the peripheral blood of breast cancer patients with advanced disease. Combined use of anti-CD146 and anti-EpCAM is likely to improve CTC detection in breast cancer patients. 


\section{Introduction}

The enumeration of circulating tumor cells (CTCs) in the peripheral blood of cancer patients is a promising tool to detect and monitor cancer earlier and less invasively than conventional methods $[2,3]$. In recent years, several assays to detect CTCs have been introduced [3]. CTCs measured with the FDA-approved CellSearch technique (Veridex ${ }^{\mathrm{TM}}$, Raritan, NJ) have prognostic value in metastatic breast cancer $[4,5]$ and changes in CTC counts during systemic therapy can serve as early marker for response [4-7].

Like most CTC detection assays in breast cancer, the CellSearch technique relies on EpCAM (epithelial cell adhesion molecule, CD326) expression on tumor cells. However, despite its robustness and proven clinical relevance, CellSearch identifies CTCs in only $60 \%$ of metastatic breast cancer patients [4]. There are two possible explanations for this; CTCs are simply not present, or they cannot be detected by this assay.

In breast cancer, five different molecular subtypes have been identified [8]. Recently, our group reported that in contrast to the other molecular subtypes, most normal-like breast cancer cell lines lack EpCAM expression and are missed using CellSearch technology [1]. Normal-like breast cancer accounted for $7.8 \%$ of all breast cancers in 344 breast cancer samples [9] thus forming a substantial breast cancer subgroup. In accordance with our preclinical findings [10], Spizzo et al., showed that $10.3 \%$ of 1715 invasive breast cancer patient samples lacked EpCAM expression [11].

Using the lack of EpCAM expression on a subset of breast cancer cells as a model for EpCAMnegative CTCs, we embarked on a search for additional markers, ultimately aiming to improve CTC detection in all breast cancer patients, irrespective of the molecular subtype of their primary tumor. As a first attempt, CD146 was our marker of choice, based on our gene expression data [1], availability of anti-CD146 ferrofluids, and a recent study by Zabouo et al [12], who showed that CD146 is expressed in a subset of primary breast cancers and is correlated with poor prognosis.

\section{Methods}




\section{Breast cancer cell lines}

In order to identify an additional marker expressed on EpCAM-negative breast cancer cells, we used our well-defined panel of 41 human breast cancer cell lines [13, 14]. The intrinsic subtype of these cell lines has been determined by gene expression profiling previously [1].

\section{CD146 mRNA expression levels}

The transcript levels of the 41 cell lines were determined with Affymetrix GeneChip Exon 1.0 ST Arrays (Affymetrix UK Ltd., Wooburn Green, UK) as described previously [14]. Additionally, expression of $C D 146$ was determined by real-time reverse transcriptase PCR. RNA was isolated from breast cancer cell lines with the RNeasy (Micro) kit (Qiagen, Valencia, CA). cDNA was prepared with the Superscript II RNase H-kit (Invitrogen, Carlsbad, CA). The resulting cDNA preparations were analyzed by real-time $\mathrm{PCR}$ in a $20 \mu \mathrm{L}$ reaction volume in a MX3000P ${ }^{\mathrm{TM}}$ Real-Time PCR System (Agilent/Stratagene, Amsterdam, The Netherlands), using TaqMan ${ }^{\text {TM }}$ Gene Expression Assays in combination with TaqMan Universal PCR Master Mix No AmpErase UNG (Applied Biosystems, Foster City, CA) according to the manufacturer's instructions. Levels of hydroxymethylbilane (HMBS), hypoxanthine phosphoribosyltransferase 1 (HPRT1) and glucuronidase, beta (GUSB) were used to control sample loading and RNA quality.

\section{CD146 protein expression levels}

Cells from cultured human breast cancer cell lines were incubated with fluorochromeconjugated monoclonal antibodies and presence of antigens was assessed as described before [1]. In brief, cells were incubated with CD34 conjugated with FITC (clone 8G12; BD Biosciences, San Jose, CA), CD146 conjugated with PE (clone P1H12; BD Biosciences) and anti-EpCAM conjugated with FITC (clone EBA-1; BD Biosciences). Cells were then analyzed on a FACSCanto flow cytometer (BD Biosciences). Unstained cells were used as a negative control.

Tissue microarrays (TMAs) were prepared in duplicate from blocks of 37 formalin-fixed, paraffin-embedded (FFPE) breast cancer cell line cells that were cultured to near confluence in complete growth medium, and from blocks of 206 FFPE primary breast cancer specimens. These blocks and 23 FFPE normal-like primary breast cancer specimens were sectioned at $4 \mu \mathrm{m}$, mounted on StarFrost slides (Waldemar Knittel-GmbH, Braunschweig, Germany), dried, 
deparaffinized in xylene and rehydrated in graded solutions of ethanol and distilled water. Specimens were pretreated with retrieval buffer (DAKO, Glostrup, Denmark) at pH 6.0 for CD146 and $\mathrm{pH} 9.0$ for $\mathrm{CD} 34$ for $40 \mathrm{~min}$ at $95-99^{\circ} \mathrm{C}$ in a water bath, cooled to room temperature for 20 min and rinsed in phosphate-buffered $\mathrm{NaCL}$ solution (PBS). This was followed by a 10-min blocking step with a $0.3 \%$ peroxide PBS solution and a 30 -min blocking step with a $5 \%$ bovine serum albumin PBS solution. Slides were stained with monoclonal antibodies against CD146 (Abcam, Cambridge, UK, N1238) and CD34 (Neomarkers, Fremont, CA, clone QBE) and counterstained with the peroxidase-conjugated Envision technique (DAKO EnVision ${ }^{\mathrm{TM}}+$ System, HRP). Each core was scored by a well-trained technician and positive staining was recorded as $100 \%, 50-99 \%, 25-50 \%, 10-25 \%, 0-10 \%$ or $0 \%$ number of positive cells.

\section{Enumeration of epithelial cells spiked in whole blood}

Blood samples containing EDTA (7.5 mL aliquots of blood) from a single healthy male donor were obtained from CellSave Preservative Tubes (Veridex LLC). To each sample, a predefined amount (50-500) of cultured human breast cancer cells was added. To determine the actual viable cell number, a $100-\mu \mathrm{L}$ aliquot of the cultured cells was incubated with $10 \mu \mathrm{L}$ of 7AAD (Sigma-Aldrich, St. Louis, MO) and $100 \mu \mathrm{L}$ of fluorescent beads (Beckman-Coulter, Miami, FL). After $15 \mathrm{~min}$ incubation at room temperature, $2 \mathrm{~mL}$ PBS was added, and samples were analyzed on a FACSCalibur flow cytometer (BD Biosciences). At least 10,000 beads were acquired to estimate the number of 7AAD-negative (viable) cells. The efficiency of retrieving the tumor cells was controlled by counting the number of viable cells that were drawn in triplicate by light microscopy after serial dilution.

To establish the number of recovered CTCs following spiking into blood from a healthy donor, samples were processed on the CellTracks AutoPrep analyzer (Veridex LLC) with the CellSearch Epithelial Cell kit (Veridex LLC). Briefly, ferrofluids coated with antibodies directed towards EpCAM were added to a blood sample, and CTCs bound to anti-EpCAM coupled ferrofluid were isolated from whole blood by magnets. Unbound cells and the remaining plasma were aspirated, followed by staining of the isolated cells with the nuclear dye 4',6-diamidino-2phenylindole (DAPI), anti-cytokeratin 8, 18 and 19 antibodies labeled with PE and CD45 
antibodies labeled with APC. After incubation, CTCs were separated magnetically once more and unbound staining reagents removed. Finally, the cells were resuspended in a MagNest Cell Presentation Device (Veridex LLC). In this device, labeled cells are oriented by two magnets for analysis in the CellSpotter Analyzer (Veridex LLC) after which the number of CTCs are enumerated according to the manufacturer's instructions.

For the detection of cells expressing CD146, anti-CD146 ferrofluid from the CellSearch Circulating Endothelial Cell kit (Veridex LLC) was used in a volume of $150 \mu \mathrm{L}$ per sample plus an excess volume of $300 \mu \mathrm{L}$. The sample was enriched for CD146-positive cells and further characterized by staining for the presence or absence of DAPI, cytokeratin 8,18 or 19 and CD45 as provided in the CellSearch Epithelial Cell kit. As CD146 enriches for circulating endothelial cells (CECs) [15], and CECs can express cytokeratin 18 [16], a marker to exclude the cytokeratin 18-expressing subset of CECs was needed. As CD34 is a pan-endothelial marker [17], CD34 conjugated with FITC (clone 8G12; BD Biosciences) was added to the CellSearch Epithelial Cell kit, in a volume of $150 \mu \mathrm{L}$ per sample plus an excess volume of $300 \mu \mathrm{L}$. The number of CTCs was determined on the CellSpotter Analyzer (Veridex LLC) according to the manufacturer's instructions. CD146+ CTCs were defined as DAPI+/CK+/CD45-/CD34-.

For combined anti-EpCAM and anti-CD146 enrichment, anti-EpCAM ferrofluids from the CellSearch Circulating Epithelial Cell kit and anti-CD146 ferrofluids from the CellSearch Circulating Endothelial Cell kit were combined in even parts to a total volume of $150 \mu \mathrm{L}$ per sample plus an excess volume of $300 \mu \mathrm{L}$. The number of CTCs in samples enriched for CD146expressing and EpCAM-expressing events was determined and defined as mentioned above.

The pivotal differences between the classic CellSearch CTC enumeration assay and the new combined anti-EpCAM/anti-CD146 assay are highlighted in figure 1.

\section{Blood samples}

Blood samples were obtained from a laboratory volunteer and patients with metastatic breast cancer seen at the outpatient clinic. For each patient, $22.5 \mathrm{~mL}$ of blood was drawn into CellSave tubes and CTCs were enumerated after enrichment using anti-EpCAM, anti-CD146 and mixed anti-EpCAM/anti-CD146 ferrofluids, using $7.5 \mathrm{~mL}$ of blood for each enrichment method. 
Additionally, 10 healthy female donors (age 23-56) were tested for CD146+ events by enumerating CTCs in $7.5 \mathrm{~mL}$ blood after enrichment with anti-CD146 ferrofluids.

This study was approved by the Erasmus MC Institutional Review Board (METC protocol 2006-248), and all donors and patients gave their written informed consent.

\section{Results}

\section{Breast cancer cell lines}

As previously reported, our cell line panel consists of 10 normal-like, 5 basal-like, 5 erbb2 and 21 luminal breast cancers as determined by gene expression profiling according to the intrinsic subtypes of Perou and Sorlie $[1,14]$. As the MDA-MB-435 normal-like cell line has been the subject of debate in literature recently with doubts about its origin [18-20], we excluded this cell line from our experiments.

\section{Candidate markers}

We have previously shown that 8 out of these 9 cell lines lack EpCAM-expression [1]. Using these normal-like cell lines as a model for non-EpCAM expressing breast cancer, several candidate markers for the assessment of EpCAM-negative CTCs were identified by comparing gene expression data between molecular subtypes. Candidate markers required membrane expression of the proteins on the EpCAM-negative breast cancer cells and absence on hematopoietic cells, or, if present, hematopoietic cells expressing the marker should be easily excluded using additional markers. Several markers fulfilled these criteria, amongst which CAV1 [1], MUC1 [1] and MCAM (CD146). Given the availability of ferrofluids coated with CD146 antibodies [21], and the possibility to exclude interference of expression by hematopoietic cells (by CD45-counterstaining) and CECs (by CD34-counterstaining), we chose to further explore this marker.

\section{CD146 and EpCAM expression}

Based on Affymetrix micro-array and qRT-PCR data, 7 out of the 9 normal-like cell lines expressed high levels of CD146 mRNA. In addition, one basal-like cell line, SUM149PT, expressed CD146, resulting in a total of 8 cell lines expressing CD146 mRNA (Table 1). 
As previously reported [1], we confirmed that cells from only 1 of the 9 normal-like cell lines (MDA-MB-157) expressed EpCAM (Table 1 and Figure 2a). Evaluation of CD146 expression by flow cytometry showed that 8 of the 9 normal-like cell lines had CD146 membrane expression at a level likely to be detected using CellSearch technology (i.e., a signal to noise ratio >5) (Table 1 and Figure 2a). Remarkably, cells from an early passage of the MDA-MB-157 cell line were CD146-positive, while cells from a later passage showed a CD146-positive and a CD146-negative population. In addition to these normal-like cell lines, two of 5 basal-like cell lines (SUM149 and SUM229) expressed both CD146 and EpCAM (Table 1 and Figure 2b).

To obtain an overview of CD146 expression across all different breast cancer subtypes, CD146 expression was determined by immunohistochemistry on a TMA of 37 breast cancer cell lines. A total of 17 cell lines stained positive for CD146, among which 8 were normal-likes, 2 basal-like, 4 luminal and 3 erbb2 cell lines. Most cell lines staining positive for CD146 showed a heterogeneous expression pattern (Figure 3a).

CD146 staining was also performed in a set of 23 normal-like primary breast tumors, 7 of which stained positive for CD146 on epithelial cells (Figure 3b).

\section{CD34 to distinguish CTCs from CECs}

The expression of CD146 on activated T-Iymphocytes [22] and CECs [23] might interfere with the detection of CD146-positive CTCs. While leukocytes can be excluded with CD45, which is already incorporated in the standard CellSearch Circulating Epithelial Cell kit, we assessed

whether CECs could be excluded with CD34, a pan-endothelial marker [15, 17]. CD34 proved to be a suitable marker to distinguish CTCs from CECs, as none of the normal-like cell lines expressed CD34 as determined by flow cytometry (Table 1). In addition, CD34 staining was completely negative on a TMA containing 37 breast cancer cell lines (data not shown). CD34 staining on 206 primary breast tumors showed less than 10\% CD34-positivity in only one tumor specimen, all other tumors were entirely CD34 negative.

\section{EpCAM-negative breast cancer cells detected with anti-CD146 ferrofluids}

To test whether EpCAM-negative breast cancer cells could be detected in healthy donor blood using CellSearch with anti-CD146 ferrofluids, a fixed number of cells from normal-like and 
basal-like cell lines was spiked into $7.5 \mathrm{~mL}$ healthy donor blood of the same donor (Figure $4 \mathrm{~b}$ ). As a control, a fixed number of luminal cells (CAMA-1) was spiked into $7.5 \mathrm{~mL}$ healthy donor blood (Figure 4b, bottom bar).

As previously reported [1], cells from 7 out of 9 normal-like cell lines could not be recovered with anti-EpCAM ferrofluids while cells from 1 of the other 2 normal-like cell lines (MDA-MB-231, Figure 4b) were partially detected (11\%). Cells from the remaining cell line, MDAMB-157, could be adequately recovered with anti-EpCAM ferrofluids, consistent with its EpCAMexpression. Of the 8 cell lines insufficiently recovered with anti-EpCAM, 5 could be detected with anti-CD146 (45-88\% recovery). Additionally, the EpCAM-expressing cell line MDA-MB-157 was partially detected by anti-CD146 (11\% recovery). After enrichment with mixed anti-EpCAM/antiCD146 ferrofluids, cells from 6/9 normal-like cell lines were recovered at rates of 46 to $100 \%$. Despite CD146 expression, cells from 3 normal-like cell lines could not be recovered (Figure 4b).

Cells of the luminal cell line CAMA-1 were detected with a recovery approaching $100 \%$ using anti-EpCAM ferrofluids. Enrichment with anti-CD146 ferrofluids alone did not result in recovery of CAMA-1 cells. The combined use of anti-CD146 and anti-EpCAM ferrofluids still enabled detection of all spiked CAMA-1 cells (Figure 4b), suggesting that mixing both ferrofluids does not greatly compromise enrichment. In accordance, 2 basal-like cell lines expressing EpCAM and CD146 could be detected with both anti-EpCAM and anti-CD146 ferrofluids as well as with a mixture of both (Figure 4b).

\section{CD146+ cells in healthy donors}

In all blood samples from 10 healthy female donors and a healthy male donor enriched with anti-CD146 ferrofluids, either in mixture or alone, a small number of CD146+/CK+/DAPI+/CD45-/CD34+ cells was identified (median 1, range 0-7), most likely accounting for a subset of CECs from the healthy donors [24]. In none of the healthy donors, CD146-expressing tumor cells, i.e., CD146+/CK+/DAPI+/CD34- cells, could be identified (data not shown).

\section{CD146+ CTCs in breast cancer patients}


To assess whether CD146-expressing CTCs do occur in breast cancer, CTCs were enumerated in 20 advanced breast cancer patients using anti-EpCAM, anti-CD146 and mixed ferrofluids. Of these 20 patients, 9 had CD146+ CTCs (Table 2). As expected, given the heterogeneity of breast cancer and the fact that some breast cancer cell lines express both EpCAM and CD146, 8 of these 9 CD146+ patients also had EpCAM+ CTCs. Enrichment with mixed ferrofluids yielded a higher CTC number compared to EpCAM enrichment alone in 8 patients (Table 2, patients 1, 2, 7, 9, 12. 13, 14 and 20). In six patients (Table 2, patients 4, 5, 15, 17, 18 and 19), the combined enrichment for CD146 and EpCAM resulted in a lower recovery of CTCs. In this small series of patients, CD146+ CTCs were present in patients with both hormone receptor positive and hormone receptor negative primary tumors.

\section{Discussion}

CTC detection with the CellSearch assay has proven its value as a prognostic marker in metastatic breast cancer $[4,5]$. Additionally, a change in CTC numbers at first follow-up of therapy is associated with outcome [7, 25-27]. Nevertheless, CTCs can be detected in only $60 \%$ of the metastatic breast cancer patients, suggesting that there is room for improvement in the CellSearch assay. As enrichment for EpCAM is the limiting first step in this and many other CTC enumeration assays, EpCAM expression on tumor cells is pivotal. However, evidence is accumulating that EpCAM is not a perfect marker for breast cancer CTCs [1, 9, 10].

In this study we demonstrated that CD146 is frequently present on EpCAM-negative breast cancer cell lines. CD146 is ubiquitously expressed on endothelial cells [28] and melanoma cells [29]. A correlation with poor prognosis has recently been found in breast cancer; of 635 primary breast tumors, 7\% were CD146-positive, and CD146 expression was associated with poor prognosis [12]. Our finding that CD146 is present on EpCAM-negative breast cancer cell lines renders it a putative marker to detect EpCAM-negative CTCs. Expression of CD146 by other cells in blood such as CECs could hinder detection of CTCs. We found that the exclusion of CK+/DAPI+/CD45-/CD34+ events after anti-CD146 enrichment resulted in CTC-negative test results in healthy donors. Hematopoietic cells expressing CD146, such as activated T- 
lymphocytes [30] and NK-cells [31], can be identified according to their bright expression of CD45.

Using the definition of CD146+/CK+/DAPI+/CD45-/CD34- for CD146-positive CTCs we were able to detect cells from five out of eight normal-like cell lines when spiked in healthy blood. For the remaining three cell lines, for which detection is limited despite CD146 expression, the assay may need further improvement, for instance by adding an additional enrichment or positive selection marker, such as different cytokeratins.

In the clinical setting, both EpCAM-positive and EpCAM-negative tumor cells are likely to be present in the blood of patients, given the heterogeneity in terms of EpCAM expression within primary tumors [10]. As a consequence, one can imagine EpCAM-negative CTCs in patients with a primary tumor that is predominantly comprised of EpCAM-positive cells and vice versa. Although we mostly observed CD146 expression in breast cancer cell lines with a normal-like subtype, the added value of CD146 is probably not limited to patients with normal-like primary tumors. CD146+ CTCs can be present in other patients too, as shown by the detection of CD146+ CTCs in patients with hormone receptor positive primary tumors, due to tumor heterogeneity or clonal selection during progression. Improved CTC detection in breast cancer using combined anti-CD146 and anti-EpCAM enrichment may be of value irrespective of the molecular subtype of the primary tumor.

To determine whether CD146-expressing CTCs are present in breast cancer patients, CTCs were captured with anti-EpCAM, anti-CD146 alone and a mixture of ferrofluids in twenty patients with advanced disease. Besides EpCAM-positive CTCs, CD146-positive CTCs were detected in 9 patients. In contrast, no CD146-expressing CTCs could be detected in healthy female controls. Although in a small series of patients, in line with the assumption that the combination of anti-EpCAM and anti-CD146 enrichment might improve CTC detection, a higher CTC count was found in 8 out of 20 patients when combining anti-EpCAM and anti-CD146 ferrofluids. However, a lower recovery was found in 6 patients using this approach. Whether this is due to technical reasons, such as suboptimal concentrations of the ferrofluids, should be evaluated before implementation into clinical studies. Importantly, the application of CD146 as an 
additional marker to detect CTCs is not restricted to the CellSearch assay alone, but may be useful for all assays depending on EpCAM-expression on the target cells.

Although based on a relatively small series of patients, the EpCAM-positive CTCs seem to outnumber the CD146-expressing CTCs. Nonetheless, even if CD146+ CTCs occur in only a small subset of patients, and may be of limited clinical relevance, minimizing false negative results is crucial for diagnostic purposes. Studies are being initiated to determine the exact incidence of CD146-positive CTCs in breast cancer patients and to reveal their clinical relevance.

In conclusion, we have shown that the majority of EpCAM-negative breast cancer cell lines can be detected using anti-CD146 ferrofluids. Furthermore, CD146-positive CTCs are present in breast cancer patients. It must be stressed that the clinical relevance of CD146positive CTCs remains to be established, and whether the prognostic value of CD146+ CTCs is equivalent to that of EpCAM+CTCs will be determined in a large clinical study. Nevertheless, the detection of CTCs, although already well established in metastatic breast cancer, can become even more relevant when detecting EpCAM-positive as well as CD146-positive CTCs. 


\section{Acknowledgments}

The authors wish to thank Antoinette Hollestelle and Anita Trapman for their precious help in providing the immunohistochemistry data. 
References

1. Sieuwerts AM, Kraan J, Bolt J, van der Spoel P, Elstrodt F, Schutte M, Martens JW, Gratama JW, Sleijfer S, Foekens JA: Anti-epithelial cell adhesion molecule antibodies and the detection of circulating normal-like breast tumor cells. Journal of the National Cancer Institute 2009, 101(1):61-66.

2. Sleijfer S, Gratama JW, Sieuwerts AM, Kraan J, Martens JW, Foekens JA: Circulating tumour cell detection on its way to routine diagnostic implementation? Eur J Cancer 2007, 43(18):2645-2650.

3. Mostert B, Sleijfer S, Foekens JA, Gratama JW: Circulating tumor cells (CTCs): detection methods and their clinical relevance in breast cancer. Cancer treatment reviews 2009, 35(5):463-474.

4. Cristofanilli M, Budd GT, Ellis MJ, Stopeck A, Matera J, Miller MC, Reuben JM, Doyle GV, Allard WJ, Terstappen LW et al: Circulating tumor cells, disease progression, and survival in metastatic breast cancer. The New England journal of medicine 2004, 351(8):781-791.

5. Cristofanilli M, Hayes DF, Budd GT, Ellis MJ, Stopeck A, Reuben JM, Doyle GV, Matera J, Allard WJ, Miller MC et al: Circulating tumor cells: a novel prognostic factor for newly diagnosed metastatic breast cancer. J Clin Oncol 2005, 23(7):1420-1430.

6. Smerage JB HD: The prognostic implications of circulating tumor cells in patients with breast cancer. Cancer Invest 2008, 26(2):109-114.

7. Rack BK, Schindlbeck C, Schneeweiss A, Hilfrich J, Lorenz R, Beckmann MW, Pantel K, Lichtenegger W, Sommer HL, Janni WL: Prognostic relevance of circulating tumor cells (CTCs) in peripheral blood of breast cancer patients before and after adjuvant chemotherapy: The German SUCCESS-Trial. J Clin Oncol 2008, 26(May 20 suppl: abstr 503).

8. Perou CM, Sorlie T, Eisen MB, van de Rijn M, Jeffrey SS, Rees CA, Pollack JR, Ross DT, Johnsen H, Akslen LA et al: Molecular portraits of human breast tumours. Nature 2000, 406(6797):747-752.

9. Smid M, Wang Y, Zhang Y, Sieuwerts AM, Yu J, Klijn JG, Foekens JA, Martens JW: Subtypes of breast cancer show preferential site of relapse. Cancer research 2008, 68(9):3108-3114.

10. Sieuwerts AM, Kraan J, Bolt J, van der Spoel P, Elstrodt F, Smid M, Timmermans M, Mostert B, Schutte M, Martens JW et al: Response: Re: Anti-Epithelial Cell Adhesion Molecule Antibodies and the Detection of Circulating Normal-Like Breast Tumor Cells. Journal of the National Cancer Institute 2009, 101(12):896-897.

11. Spizzo G, Went P, Dirnhofer S, Obrist P, Simon R, Spichtin H, Maurer R, Metzger $U$, von Castelberg B, Bart $R$ et al: High Ep-CAM expression is associated with poor prognosis in node-positive breast cancer. Breast cancer research and treatment 2004, 86(3):207-213.

12. Zabouo G, Imbert AM, Jacquemier J, Finetti P, Moreau T, Esterni B, Birnbaum D, Bertucci F, Chabannon C: CD146 expression is associated 
with a poor prognosis in human breast tumors and with enhanced motility in breast cancer cell lines. Breast Cancer Res 2009, 11(1):R1.

13. Elstrodt F, Hollestelle A, Nagel JH, Gorin M, Wasielewski M, van den Ouweland A, Merajver SD, Ethier SP, Schutte M: BRCA1 mutation analysis of $\mathbf{4 1}$ human breast cancer cell lines reveals three new deleterious mutants. Cancer research 2006, 66(1):41-45.

14. Hollestelle A, Nagel JH, Smid M, Lam S, Elstrodt F, Wasielewski M, Ng SS, French PJ, Peeters JK, Rozendaal MJ et al: Distinct gene mutation profiles among luminal-type and basal-type breast cancer cell lines. Breast cancer research and treatment $2009 \mathrm{Jul}$ 11. [Epub ahead of print].

15. Strijbos MH, Gratama JW, Kraan J, Lamers CH, den Bakker MA, Sleijfer S: Circulating endothelial cells in oncology: pitfalls and promises. British journal of cancer 2008, 98(11):1731-1735.

16. Brakenhoff $R H$, Stroomer JG, ten Brink $C$, de Bree R, Weima SM, Snow $G B$, van Dongen GA: Sensitive detection of squamous cells in bone marrow and blood of head and neck cancer patients by E48 reverse transcriptase-polymerase chain reaction. Clin Cancer Res 1999, 5(4):725-732.

17. Fina L, Molgaard HV, Robertson D, Bradley NJ, Monaghan P, Delia D, Sutherland DR, Baker MA, Greaves MF: Expression of the CD34 gene in vascular endothelial cells. Blood 1990, 75(12):2417-2426.

18. Ross DT, Scherf U, Eisen MB, Perou CM, Rees C, Spellman P, lyer V, Jeffrey SS, Van de Rijn M, Waltham $M$ et al: Systematic variation in gene expression patterns in human cancer cell lines. Nature genetics 2000, 24(3):227-235.

19. Rae JM, Creighton CJ, Meck JM, Haddad BR, Johnson MD: MDA-MB435 cells are derived from M14 melanoma cells--a loss for breast cancer, but a boon for melanoma research. Breast cancer research and treatment 2007, 104(1):13-19.

20. Chambers AF: MDA-MB-435 and M14 cell lines: identical but not M14 melanoma? Cancer Res 2009, 69(13):5292-5293.

21. Rowand JL, Martin G, Doyle GV, Miller MC, Pierce MS, Connelly MC, Rao C, Terstappen LW: Endothelial cells in peripheral blood of healthy subjects and patients with metastatic carcinomas. Cytometry A 2007, 71(2):105-113.

22. Pickl WF, Majdic O, Fischer GF, Petzelbauer P, Fae I, Waclavicek M, Stockl J, Scheinecker C, Vidicki T, Aschauer H et al: MUC18/MCAM (CD146), an activation antigen of human T lymphocytes. J Immunol 1997, 158(5):2107-2115.

23. Smirnov DA, Foulk BW, Doyle GV, Connelly MC, Terstappen LW, O'Hara SM: Global gene expression profiling of circulating endothelial cells in patients with metastatic carcinomas. Cancer Res 2006, 66(6):29182922.

24. SAGE anatomic viewer: KRT18 expression in vascular tissue. http://cgap.nci.nih.gov/SAGE/AnatomicViewer 
25. Hayes DF, Cristofanilli M, Budd GT, Ellis MJ, Stopeck A, Miller MC, Matera J, Allard WJ, Doyle GV, Terstappen LW: Circulating tumor cells at each follow-up time point during therapy of metastatic breast cancer patients predict progression-free and overall survival. Clin Cancer Res 2006, 12 (14 Pt 1):4218-4224.

26. Budd GT, Cristofanilli M, Ellis MJ, Stopeck A, Borden E, Miller MC, Matera J, Repollet M, Doyle GV, Terstappen LW et al: Circulating tumor cells versus imaging--predicting overall survival in metastatic breast cancer. Clin Cancer Res 2006, 12(21):6403-6409.

27. Pierga JY, Bidard FC, Mathiot C, Brain E, Delaloge S, Giachetti S, de Cremoux P, Salmon R, Vincent-Salomon A, Marty M: Circulating tumor cell detection predicts early metastatic relapse after neoadjuvant chemotherapy in large operable and locally advanced breast cancer in a phase II randomized trial. Clin Cancer Res 2008, 14(21):7004-7010.

28. Bardin N, George F, Mutin M, Brisson C, Horschowski N, Frances V, Lesaule G, Sampol J: S-Endo 1, a pan-endothelial monoclonal antibody recognizing a novel human endothelial antigen. Tissue antigens 1996, 48(5):531-539.

29. Lehmann JM, Riethmuller G, Johnson JP: MUC18, a marker of tumor progression in human melanoma, shows sequence similarity to the neural cell adhesion molecules of the immunoglobulin superfamily. Proceedings of the National Academy of Sciences of the United States of America 1989, 86(24):9891-9895.

30. Elshal MF, Khan SS, Raghavachari N, Takahashi Y, Barb J, Bailey JJ, Munson PJ, Solomon MA, Danner RL, McCoy JP, Jr.: A unique population of effector memory lymphocytes identified by CD146 having a distinct immunophenotypic and genomic profile. $B M C$ Immunol 2007, 8:29.

31. Despoix N, Walzer T, Jouve N, Blot-Chabaud M, Bardin N, Paul P, Lyonnet L, Vivier E, Dignat-George F, Vely F: Mouse CD146/MCAM is a marker of natural killer cell maturation. European journal of immunology 2008, 38(10):2855-2864. 
Table 1 CD146 mRNA and CD146, CD34 and EpCAM protein expression in normal-like and basal-like breast cancer cell lines.

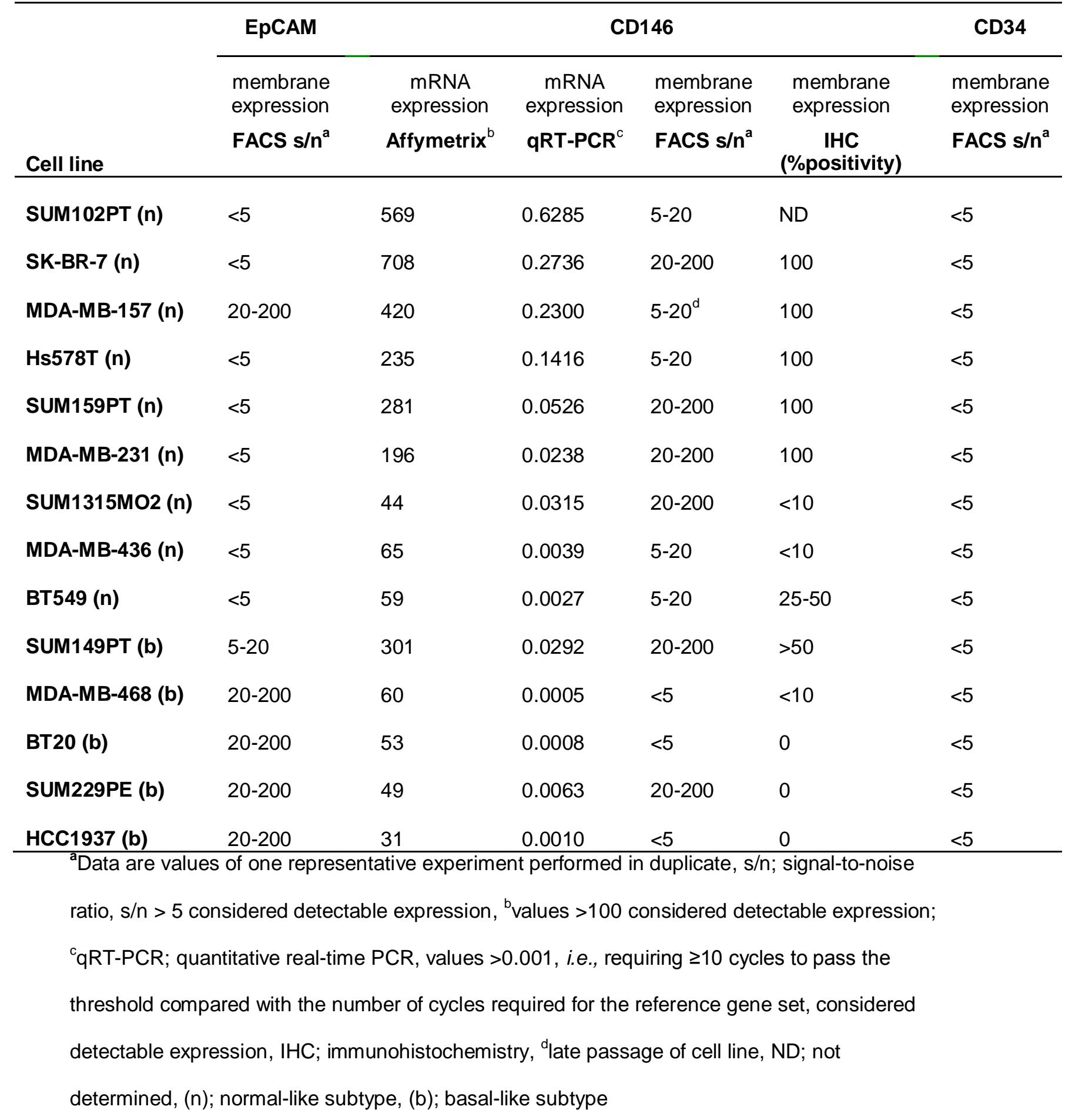


Table 2 CTC counts with anti-EpCAM, anti-CD146 and mixed anti-EpCAM/CD146 ferrofluids for 20 advanced breast cancer patients, and their primary tumor characteristics

\begin{tabular}{|c|c|c|c|c|c|c|}
\hline \multirow{2}{*}{$\begin{array}{l}\text { Patient } \\
\text { number }\end{array}$} & \multicolumn{3}{|c|}{$\begin{array}{l}\text { Primary tumor } \\
\text { characteristics }\end{array}$} & \multicolumn{3}{|c|}{ CTC count } \\
\hline & $\mathrm{ER}^{\mathrm{a}}$ & $\mathrm{PR}^{\mathrm{b}}$ & Her2 & EpCAM+ & CD146+ & EpCAM/CD146+ \\
\hline 1 & + & + & - & 15 & 1 & 17 \\
\hline 2 & + & - & + & 19 & 1 & 25 \\
\hline 3 & + & - & - & 0 & 4 & 1 \\
\hline 4 & + & + & - & 38 & 5 & 20 \\
\hline 5 & + & + & - & 47 & 2 & 30 \\
\hline 6 & + & + & NA & 2 & 1 & 1 \\
\hline 7 & - & + & - & 28 & 5 & 40 \\
\hline 8 & + & NA & + & 0 & 0 & 0 \\
\hline 9 & + & - & - & 54 & 0 & 75 \\
\hline 10 & + & + & - & 0 & 0 & 0 \\
\hline 11 & + & + & - & 0 & 0 & 0 \\
\hline 12 & + & + & - & 0 & 0 & 1 \\
\hline 13 & + & + & - & 0 & 0 & 1 \\
\hline 14 & + & + & - & 1 & 0 & 2 \\
\hline 15 & + & + & NA & 2 & 0 & 1 \\
\hline 16 & - & - & NA & 0 & 0 & 0 \\
\hline 17 & + & + & - & 19 & 0 & 11 \\
\hline 18 & + & + & - & 155 & 24 & 148 \\
\hline 19 & + & + & - & 107 & 3 & 94 \\
\hline 20 & + & + & - & 0 & 0 & 1 \\
\hline
\end{tabular}


Fig. 1 Setup of the CellSearch CTC enumeration assay (left column) versus the new antiEpCAM/anti-CD146 assay (right column)

Description of the makers used in each assay for enrichment, positive selection and negative selection, and the cell type associated with these selection criteria. CK; cytokeratin 
Fig. 2 EpCAM and CD146 membrane expression assessed by flow-cytometry

Black histograms show unstained cells, red histograms show expression on EpCAM-stained cells

(left panel) and CD146 stained cells (right panel) of normal-like (a) and basal-like (b) cell lines.

X-axis; fluorescence intensity; Y-axis; number of counted cells 
Fig. 3 CD146 staining

(a) Representative pictures of indicated cell lines stained for CD146 (brown). Both cell lines shown are of normal-like molecular subtype (b) Representative pictures of two primary normal-like breast tumors stained for CD146 (brown) 
Fig. 4 EpCAM and CD146 membrane expression in normal-like (n), basal (b) and luminal (I) cell lines (a), and recovery of these cell lines $(b)$

(a): Open bar, EpCAM membrane expression, closed bar; CD146 membrane expression, s/n;

signal-to-noise ratio, $\mathrm{s} / \mathrm{n}>5$ considered detectable expression.

(b): Open bar, recovery with anti-EpCAM ferrofluids, closed bar; recovery with anti-CD146

ferrofluids, hatched bar; recovery with anti-EpCAM/anti-CD146 ferrofluids

Fig. 1

enrichment

positive

selection

negative

selection

cell type
$7.5 \mathrm{ml}$ whole blood

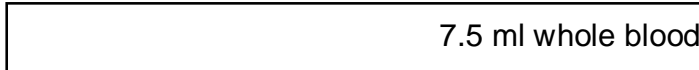

anti-EpCAM ferrofluid

anti-EpCAM + anti-CD146 ferrofluid
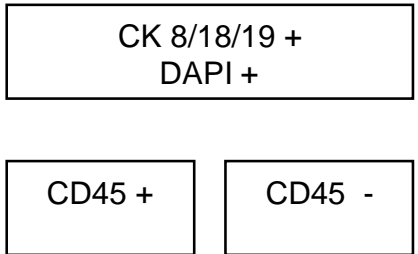

leukocyte

CTC
CK 8/18/19+

$\mathrm{DAPI}+$
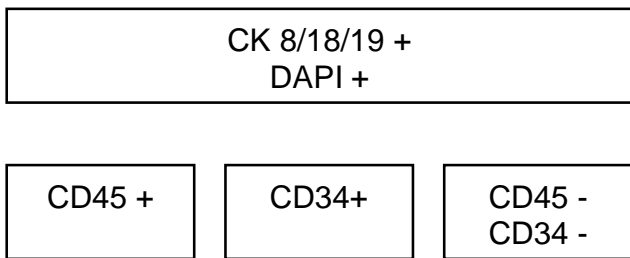

CD34 -

leukocyte
CEC

CTC 


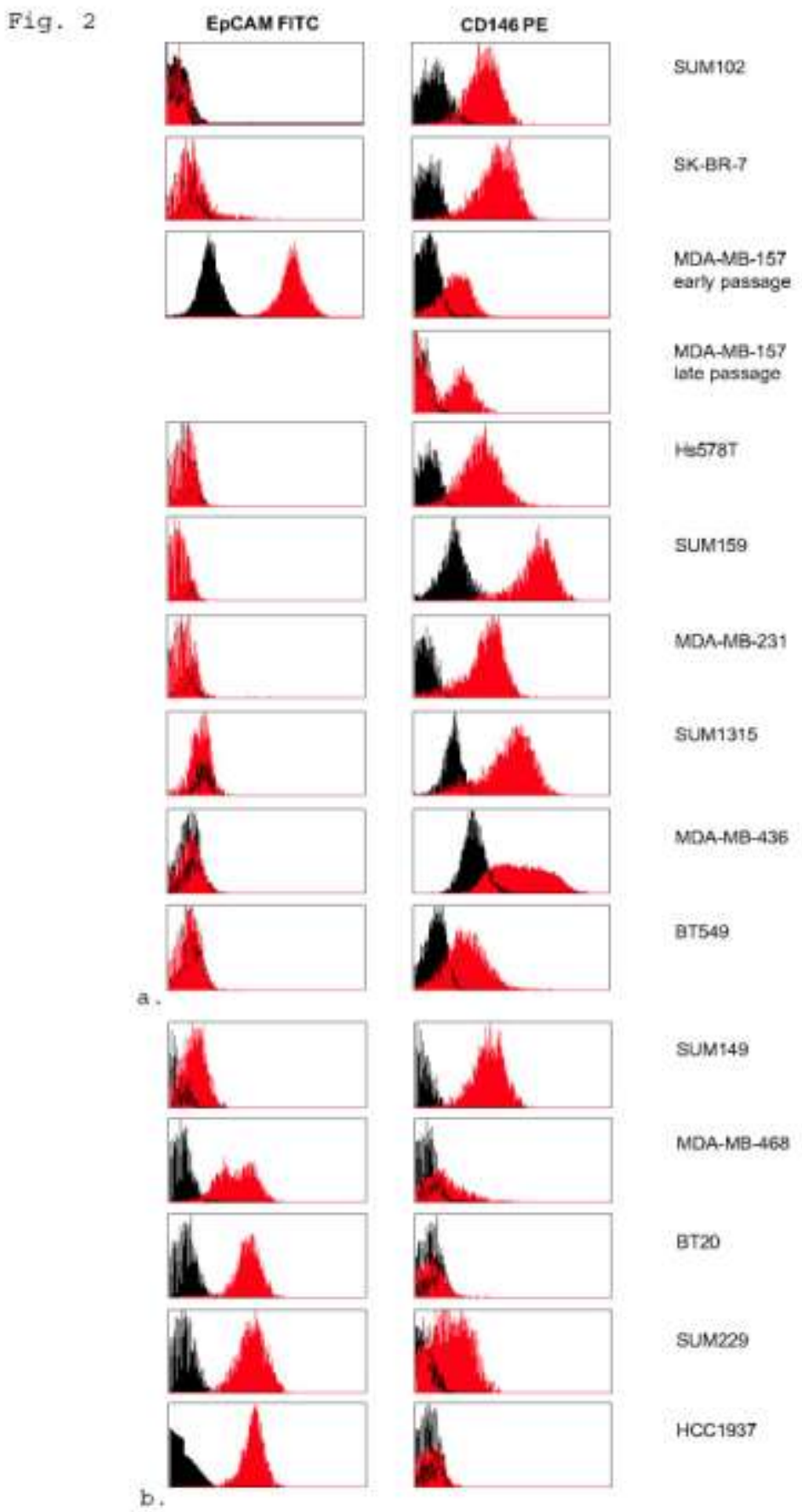

Fig. 3 


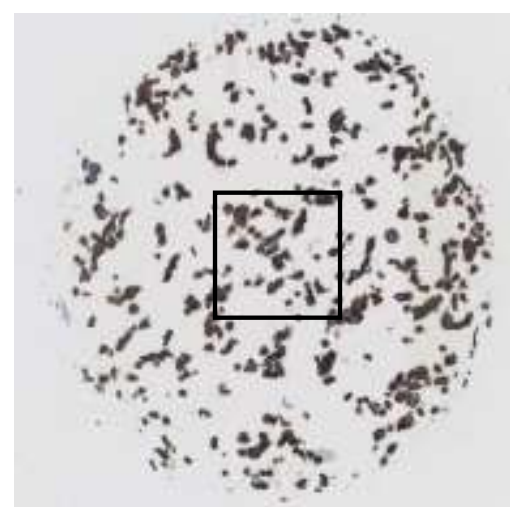

a. SK-BR-7 (100\% positive)

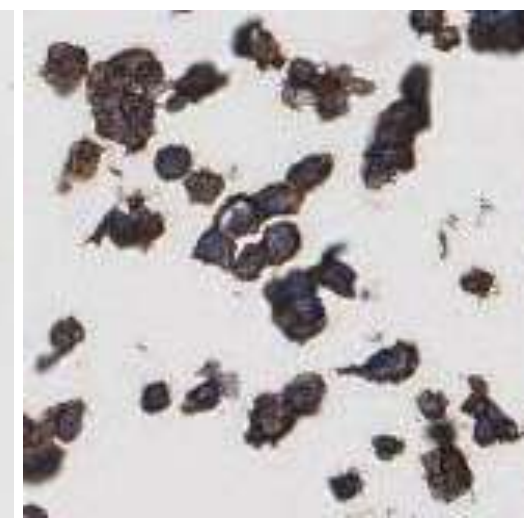

Inset: SK-BR-7

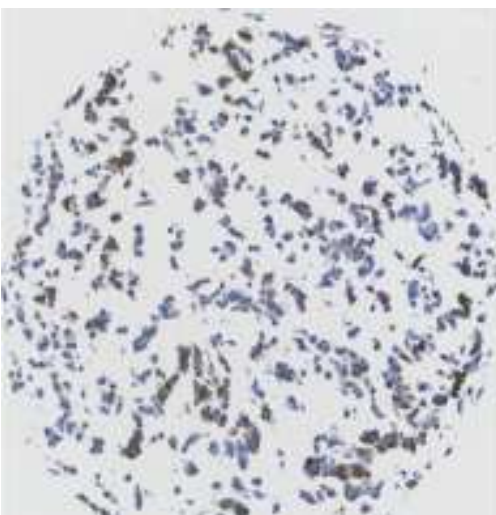

BT549 (25-50\% positive)

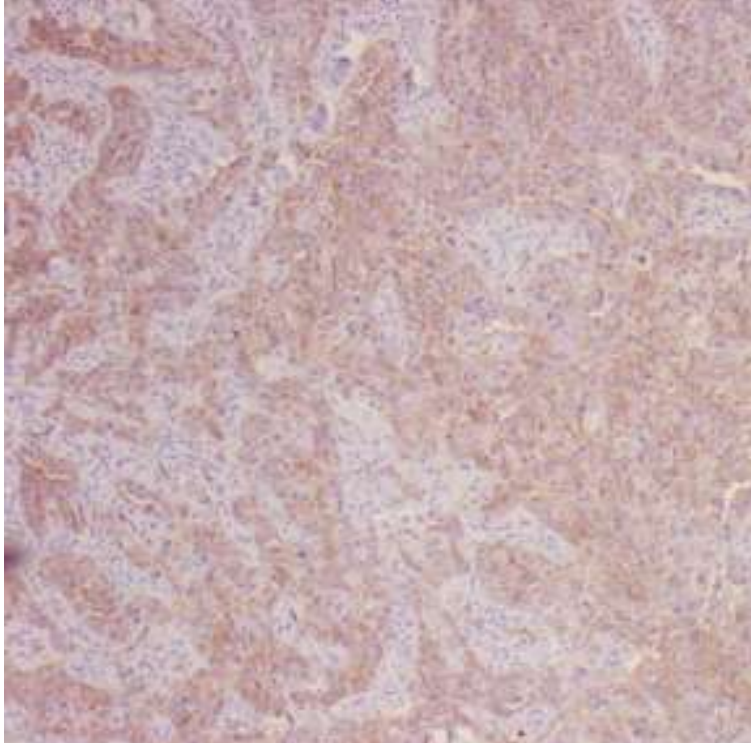

Primary breast tumor $1(5 x)$

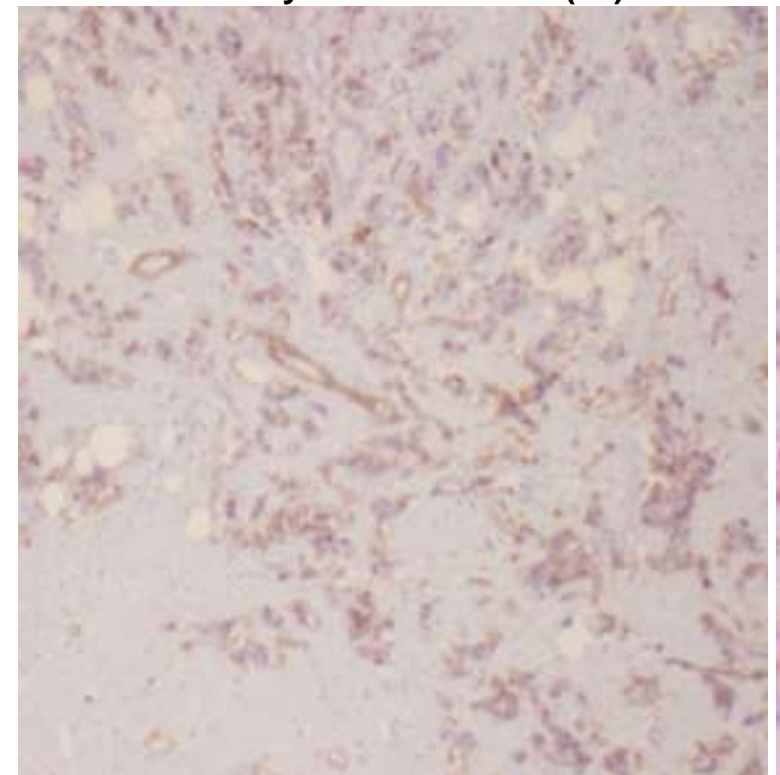

b.

Primary breast tumor 2 (5x)

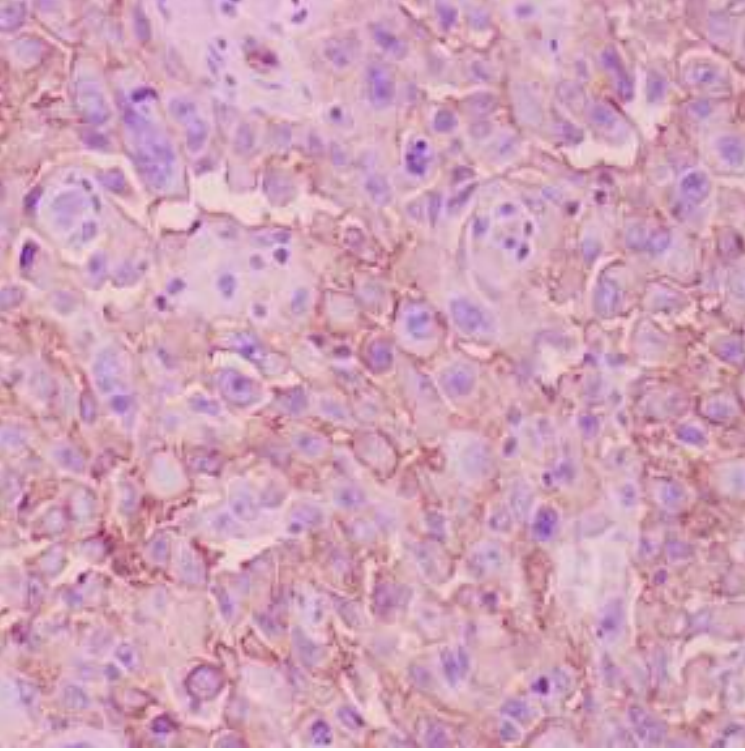

Primary breast tumor 1 (20x)

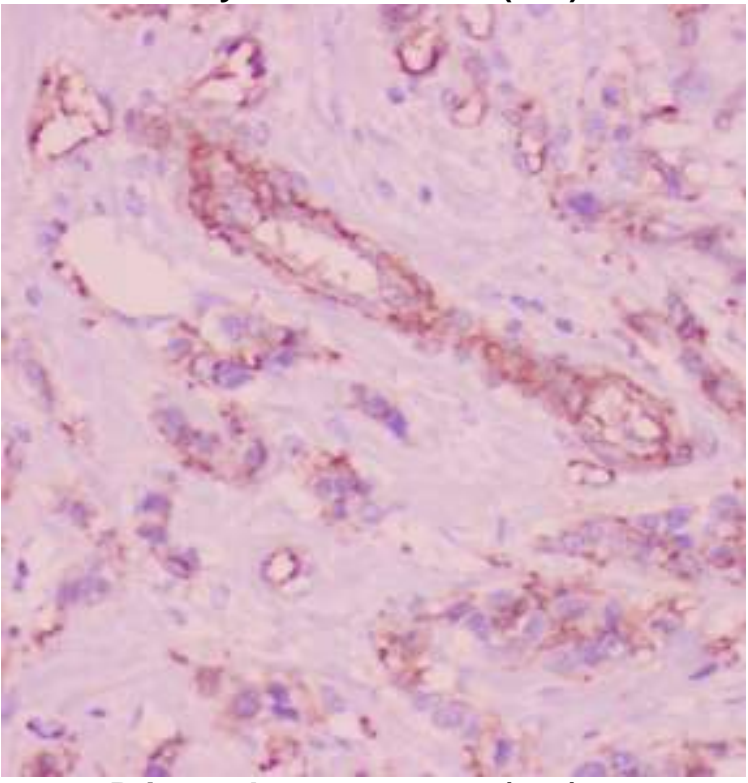

Primary breast tumor 2 (20x) 
Fig. 4
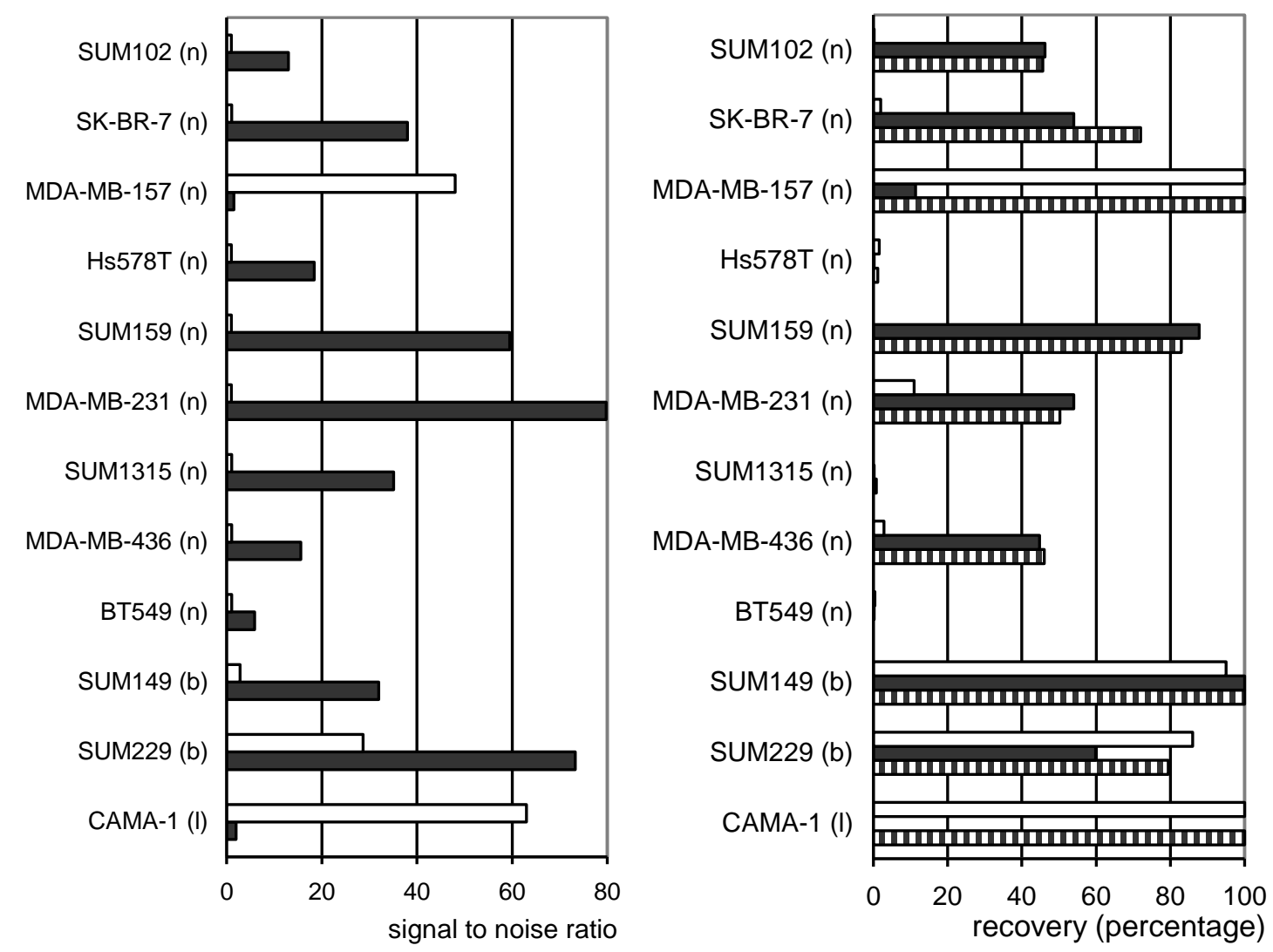

a.

b.

Table 1 CD146 mRNA and CD146, CD34 and EpCAM protein expression in normal-like and basal-like breast cancer cell lines.

\begin{tabular}{|c|c|c|c|c|c|c|}
\hline \multirow[b]{3}{*}{ Cell line } & \multirow{2}{*}{$\begin{array}{c}\text { EpCAM } \\
\begin{array}{l}\text { membrane } \\
\text { expression }\end{array}\end{array}$} & \multicolumn{4}{|c|}{ CD146 } & \multirow{3}{*}{$\begin{array}{c}\text { CD34 } \\
\text { membrane } \\
\text { expression } \\
\text { FACS s/n }\end{array}$} \\
\hline & & $\begin{array}{c}\text { mRNA } \\
\text { expression }\end{array}$ & $\begin{array}{c}\text { mRNA } \\
\text { expression }\end{array}$ & $\begin{array}{l}\text { membrane } \\
\text { expression }\end{array}$ & $\begin{array}{l}\text { membrane } \\
\text { expression }\end{array}$ & \\
\hline & FACS $s / n^{a}$ & Affymetrix $^{b}$ & qRT-PCR ${ }^{c}$ & FACS $s / n^{a}$ & $\begin{array}{c}\text { IHC } \\
\text { (\%positivity) }\end{array}$ & \\
\hline SUM102PT (n) & $<5$ & 569 & 0.6285 & $5-20$ & ND & $<5$ \\
\hline SK-BR-7 (n) & $<5$ & 708 & 0.2736 & $20-200$ & 100 & $<5$ \\
\hline MDA-MB-157 (n) & $20-200$ & 420 & 0.2300 & $5-20^{d}$ & 100 & $<5$ \\
\hline Hs578T (n) & $<5$ & 235 & 0.1416 & $5-20$ & 100 & $<5$ \\
\hline SUM159PT (n) & $<5$ & 281 & 0.0526 & $20-200$ & 100 & $<5$ \\
\hline MDA-MB-231 (n) & $<5$ & 196 & 0.0238 & $20-200$ & 100 & $<5$ \\
\hline
\end{tabular}




\begin{tabular}{|c|c|c|c|c|c|c|}
\hline SUM1315MO2 (n) & $<5$ & 44 & 0.0315 & $20-200$ & $<10$ & $<5$ \\
\hline MDA-MB-436 (n) & $<5$ & 65 & 0.0039 & $5-20$ & $<10$ & $<5$ \\
\hline BT549 (n) & $<5$ & 59 & 0.0027 & $5-20$ & $25-50$ & $<5$ \\
\hline SUM149PT (b) & $5-20$ & 301 & 0.0292 & $20-200$ & $>50$ & $<5$ \\
\hline MDA-MB-468 (b) & $20-200$ & 60 & 0.0005 & $<5$ & $<10$ & $<5$ \\
\hline BT20 (b) & $20-200$ & 53 & 0.0008 & $<5$ & 0 & $<5$ \\
\hline SUM229PE (b) & $20-200$ & 49 & 0.0063 & $20-200$ & 0 & $<5$ \\
\hline HCC1937 (b) & $20-200$ & 31 & 0.0010 & $<5$ & 0 & $<5$ \\
\hline \multicolumn{7}{|c|}{${ }^{a}$ Data are values of one representative experiment performed in duplicate, s/n; signal-to-noise } \\
\hline
\end{tabular}

Table 2 CTC counts with anti-EpCAM, anti-CD146 and mixed anti-EpCAM/CD146 ferrofluids for 20 advanced breast cancer patients, and their primary tumor characteristics

\begin{tabular}{lcccccc}
\hline \multirow{2}{*}{$\begin{array}{l}\text { Patient } \\
\text { number }\end{array}$} & \multicolumn{3}{c}{$\begin{array}{c}\text { Primary tumor } \\
\text { characteristics }\end{array}$} & \multicolumn{5}{c}{ CTC count } \\
\cline { 2 - 7 } & ER $^{\mathrm{a}}$ & $\mathrm{PR}^{\mathrm{b}}$ & Her2 & EpCAM+ & CD146+ & EpCAM/CD146+ \\
\hline $\mathbf{1}$ & + & + & - & 15 & 1 & 17 \\
$\mathbf{2}$ & + & - & + & 19 & 1 & 25 \\
$\mathbf{3}$ & + & - & - & 0 & 4 & 1 \\
$\mathbf{4}$ & + & + & - & 38 & 5 & 20 \\
$\mathbf{5}$ & + & + & - & 47 & 2 & 30 \\
$\mathbf{6}$ & + & + & $\mathrm{NA}$ & 2 & 1 & 1 \\
$\mathbf{7}$ & - & + & - & 28 & 5 & 40 \\
$\mathbf{8}$ & + & $\mathrm{NA}$ & + & 0 & 0 & 0
\end{tabular}




\begin{tabular}{lllllll}
9 & + & - & - & 54 & 0 & 75 \\
10 & + & + & - & 0 & 0 & 0 \\
11 & + & + & - & 0 & 0 & 0 \\
12 & + & + & - & 0 & 0 & 1 \\
13 & + & + & - & 0 & 0 & 1 \\
14 & + & + & - & 1 & 0 & 2 \\
15 & + & + & 2 & 0 & 1 \\
16 & - & - & $N A$ & 0 & 0 & 0 \\
17 & + & - & 19 & 0 & 11 \\
18 & + & + & - & 155 & 24 & 148 \\
19 & + & + & 107 & 3 & 94 \\
20 & + & + & - & 0 & 0 & 1 \\
\hline${ }^{a}$ ER; estrogen receptor, ${ }^{b}$ PR; progesterone receptor, NA; not available &
\end{tabular}

